\title{
Educational robots and children's imagery: a preliminary investigation in the first year of primary school
}

\author{
Filippo Bruni ${ }^{\mathrm{a}}$, Michela Nisdeo ${ }^{\mathrm{b} 1}$ \\ ${ }^{a}$ University of Molise, Campobasso,Italy, filippo.bruni@unimol.it,0000-0002-5034-849X \\ ${ }^{b}$ MIUR, IC Colozza, Campobasso, Italy,michelanis@gmail.
}

\begin{abstract}
This study, within the dual context of media education and the use of educational robots, presents a preliminary investigation relating children's imagery of robots achieved through the analysis of 44 drawings done by children in the first year of primary school. In addition to identifying a set of analytical criteria to be further investigated, the research shows (i) some sources of children's imagery about robots, (ii) the difficulties of a specific age group to clearly distinguish between toys, robots and human beings and (iii) some possible indications for educational paths.
\end{abstract}

Keywords: media education; teaching method; child imagination; robots; toys

\section{Media Education for robotics?}

In February 2017, the European Parliament approved the resolution on Civil Law Rules on Robotics (European Parliament 2017), giving an eloquent sign of how the spreading use of robots has gone far beyond the limited scope of utilising technologies in educational paths. Retracing the resolution in some of its stages can provide a useful framework that will allow achieving more targeted interventions in the field of education.

The first point to emphasise is the belief that robots will exert an even broader and positive role in people's lives and jobs: "whereas the development of robotics and AI [artificial intelligence] may have the potential to transform lives and work practices, raise efficiency, savings, and safety levels, provide enhanced level of services in the short to medium term robotics and AI promise to bring benefits of efficiency and savings, not only in production and commerce, but also in areas such as transport, medical care, rescue, education and farming" (European Parliament 2017). Significant in this respect is also the list of different types of robots employed and the object of specific insights: unmanned aerial vehicles such as drones, robots designed to assist in healthcare for the elderly, surgical robots and cyber physical systems (CPSs) that can be worn or implanted in the human body.

The second point to outline is that, although the positive potential of robots is acknowledged, such a pervasive diffusion implies the awareness of a number of risks. Sherry Turkle had already reported the loss of authentic forms of interpersonal relationship in her work on social robots for elderly care (Turkle 2011). This can actually be an aspect that deserves to be reported among the many tangible concerns that range from an economic and political dimension, with a possible concentration of wealth and power in a few hands, to legal issues related to the robot's responsibility for its actions at the moment in which it acts autonomously. The resolution of the European Parliament is moving in the direction of shared integration between human and robotic capability, where robots should not be thought of as human substitutes. The implementation of such an integration is not exempt from delicate issues related to the emotional dimension of human-robot relationships, in particular within certain groups of people: "special attention should be paid to the possible development of an emotional connection between humans and robots - particularly in vulnerable groups (children, the elderly and people with disabilities) - and highlights the issues raised by the serious emotional or physical impact that this emotional attachment could have on humans" (European Parliament 2017).

The third point to draw attention to is that educational processes have a much more important role than the reflection on the use of robots (namely, innovative technology) as a teaching tool. The first level is certainly the one related to the acquisition of technical and professional skills: "the growth in the robotics requires Member States to develop more

\footnotetext{
1 Filippo Bruni wrote paragraphs 1.2, 3, 5, 6. Michela Nisdeo wrote paragraph 4.
} 
flexible training and education systems so as to ensure that skill strategies match the needs of the robot economy", but to not be considered only as instrumental skills. What is reported, and this is the second level of great interest, is the importance of paying attention to gender differences: "getting more young women interested in a digital career and placing more women in digital jobs would benefit the digital industry, women themselves and Europe's economy" (European Parliament 2017). A third level, which also deserves to be strongly emphasised, is the importance of promoting flexible and creative skills: "importance of the flexibility of skills and of social, creative and digital skills in education; is certain that, in addition to schools imparting academic knowledge, lifelong learning needs to be achieved through lifelong activity" (European Parliament 2017). In a logic that is typical of Media Education. what should be promoted are dimensions that are not immediately, strictly and exclusively instrumental to the economic process and that can draw on, going beyond the document of the resolution, the informal dimension of learning bringing to light, as will be pointed out later on, preconceptions and also knowledge of the imaginary dimension.

What emerges in the end - this can be summarised as the main suggestion offered by the resolution of the European Parliament in relation to education - is the need for a dual approach to robotics: on the one hand, to train in using robotics (and it is not only a training related to technical aspects but an approach that crosses multiple disciplines and aspects ranging from the computing dimension to the legal, ethical, psychological, social ones...) and, on the other, to examine how robotics can, in association with other digital technologies, support learning processes.

\section{Educational robotics: beyond coding}

In developing the latter orientation, what is noticed is a growing attention towards educational robotics, as proven, in the international context, by some reviews on the topic (Benitti 2012, Toh et al. 2016) and, in the Italian context, by an increasing number of works (e.g. Alessandri 2015, Grimaldi 2015, Pennazio 2016, Marcianò 2017), but there are two limits to recognise.

The first consists in considering robotics as an educational activity separate from the other ones: "teachers who implemented robotics activities in schools witness that they felt after-school classes or special in-school activities for certain students are more convenient" (Alimisis 2013, p. 65).

The second consists in connecting educational robotics only to some subject areas: "until now most of the applications of robotic technology in education have focused on supporting the teaching of subjects that are closely related to the robotics field, such as robot programming, robot construction or mechatronics" (Alimis 2013, p. 66, Benitti 2012, p. 981).

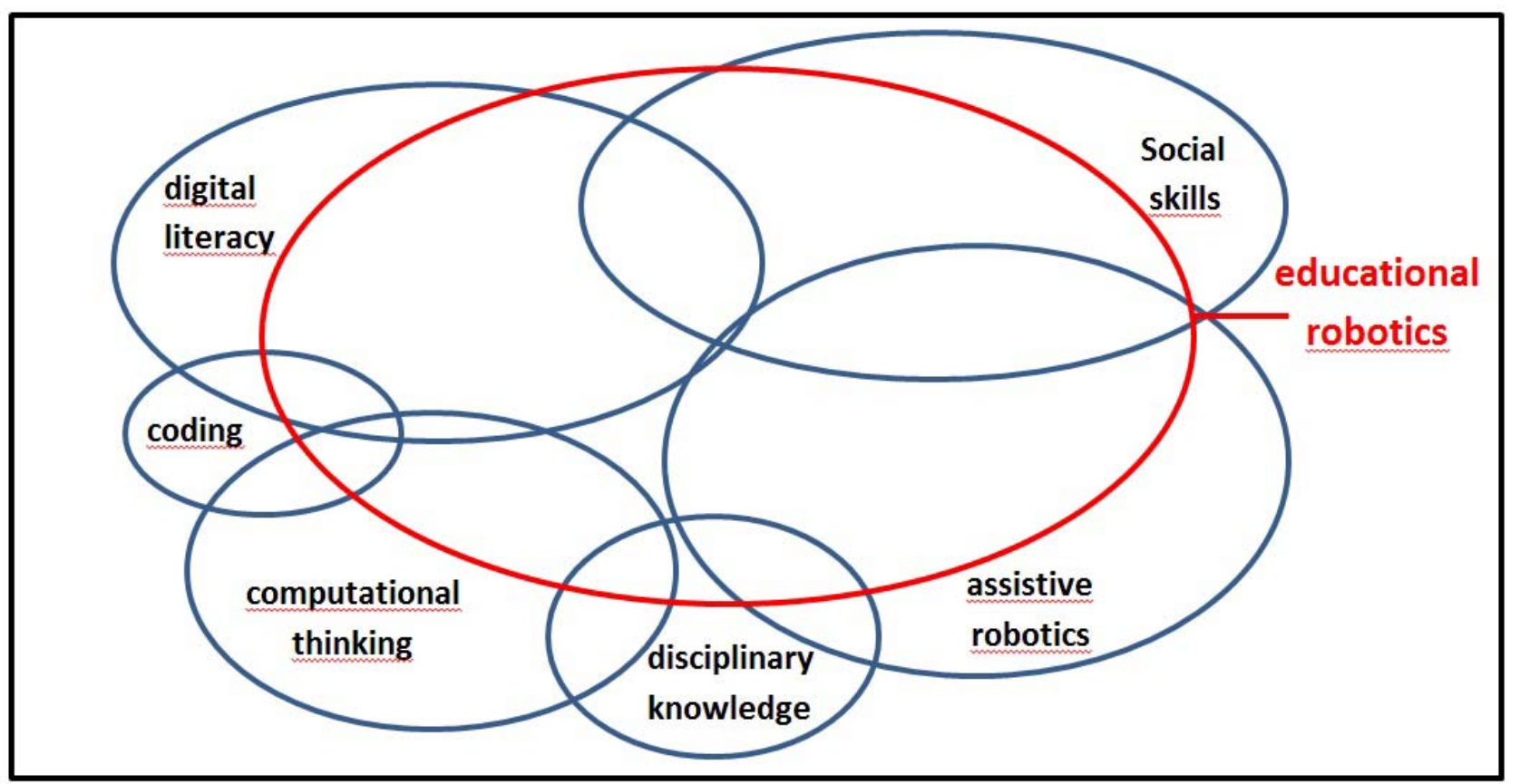

Fig. 1 Educational robotics as transverse activity.

If, in the first instance, the link with coding appears to be immediate, even more so does the reference to computational thinking, leading to a greater openness. Computational thinking goes beyond coding, from which it clearly wants to diversify because it "involves solving problems, designing systems, and understanding human behavior, by drawing on the concepts fundamental to computer science" (Wing 2006, p. 33). Although the main subject 
area of reference is scientific, the perspective is that of an interdisciplinary approach: "computational thinking will be a reality when it is so integral to human endeavors it disappears as an explicit philosophy" (Wing 2006, p. 33). However, this implies for educational robotics to relate not only to the science, technology, engineering and mathematics (STEM) program areas but, in a logic of openness and transversality towards all curricular subjects, even those most seemingly unexpected such as second language learning (Toh, p. 152). The same reference to digital literacy cannot be interpreted in a reductive manner: in line with Jenkins, digital literacy, from a vision that is strongly linked to the technical aspects of information technology, deals with a participatory culture where soft skills take on a central role (Jenkins et al. 2009, p. 19). A particular reference finally goes to a special use of robotics: when considering people with learning disabilities, the acquisition of knowledge and skills opens a new horizon for robotics, that of assistive robotics (Besio 2008, Cook and Polgar 2015).

Moreover, current research has identified areas of well-structured application: "In terms of developing skills through robotics, we can see that the skills involved are focused on: (i) thinking skills (observation, estimation and manipulation), (ii) science process skills/problem solving approaches (like solution of evaluation, hypothesis generation, hypothesis testing and control of variables), and (iii) social interaction/teamwork skills" (Benitti p. 986), however, organically linked to the twenty-first century needs (Euguchi 2014).

In conclusion (Fig. 1), educational robotics is transversal to coding activities, to computational thinking (which includes thinking skills and problem solving), to all curricular subjects beyond the scientific ones, to the digital skills characterising the twenty-first century, to social skills, and lastly, to assistive robotics.

\section{Robots and children's imagery: a prospective for research}

The scenario outlined here suggests a double priority. The first is to educate in robots, from the perspective of media education. The second is to facilitate the purposeful use of robots as a teaching tool, being aware that "the gain in learning by students is not guaranteed just by the simple application of robotics" and that "the observed results are absolutely inconclusive" (Benitti 2012, p. 986). The priority becomes even more urgent when referring to children, at a particularly vulnerable age range; consequently, special attention is required in both directions.

In this respect, a series of questions should be addressed, although the answers are preliminary to both media education paths and educational use of robots: what do children think of robots? What influences their thought of robots? What awareness do they have about robots? How can one bring out the way they conceive them? Being able to understand how children conceive robots implies, on the one hand, to identify the elements that are derived from the adult world and, on the other, if and how they are processed by the children and with what level of awareness. This data can be very useful in understanding how to introduce robots in learning paths, in the logic of linking the training needs with the didactic planning design and the related methodology in which to insert the robot (Thomaz et al. 2009).

The category of imagery and childhood imagination is very useful in this direction. Imagery is often understood as a fictional and illusory dimension, but in fact, it is a way to give form to emotions, ideas, feelings, images and actions differing from, without necessarily being opposed to, forms of abstract rationality. Based on Wunenburger's approach, imagery can be defined as "un ensemble de productions, mentales ou matérialisées dans des œuvres, à base d'images visuelles (tableau, dessin, photographie) et langagières (métaphore, symbole, récit), formant des ensembles cohérents et dynamiques" (Wunenburger 2003, p. 5), equipped with its own logic (“L'imaginaire n'est pas d'emblée une forme de l'irrationnel mais doit plutôt être vu comme un espace-temps «alogique », dont on peut mettre au jour les contraintes", Wunenburger 2003, p. 22) and functions. In general terms, the faculty of imagining has the function to place ourselves in an intermediate space between the immediately perceived reality on the one side and the conceptual and abstract thinking on the other: 'L'imaginaire nous permet d'abord de nous détacher de l'immédiat, du réel présent et perçu, sans nous enfermer dans les abstractions de la pensée" (Wunenburger 2003, p. 33). More specifically, Wunenburger identifies three guidelines: the first is related to play: "l'imaginaire ouvre la porte à la sphère d'activités gratuites, désintéressées, dont le jeu, le divertissement et les arts sont les exemples les plus universels” (Wunenburger 2003, p. 33). The second is linked to the cognitive dimension, allowing going beyond the shortcomings of science. The third guideline is defining - practical - and refers to the way in which society functions: "Sans une enveloppe, une surcharge, un horizon d'imaginaire, la vie en société risquerait fort d'apparaître comme bien arbitraire et fragile. Ni l'autorité, ni la justice, ni le travail ne pourraient trouver leur place dans la société s'ils n'étaient à un degré ou un autre tissés dans l'imaginaire" (Wunenburger 2003, p. 38). Children's imagination is naturally closer to the visual dimension rather than the linguistic one and, in relation to the functions, prefers the ludic dimension to the others.

The relationship between robotics and children's imagination is an issue scarcely addressed in research. Works on the relationship between iconography and children's imagination can be found (for the Italian context, see Lepri 2016), but on the robotics-children's imagination relationship, the only research reports found with empirical data are those of Woods (2006) and Fortunati et al. (2015). Woods (2006), through a questionnaire, required 159 children aged 911 years to analyse 40 images of robots. The study of Fortunati et al. (2015), again through a questionnaire, explicitly investigated the imagination of 704 children aged 9-14 years. 


\section{The idea behind the research: drawing a robot}

The research was based on the need to set a proper design of an educational path in which to use robots. In order to identify the proper type of robot to use, it is appropriate to make a choice according to not only the learning goals but also children's perception of robots. The investigation on children's imagination in relation to robots represents a phase that can provide functional data on the processing and management of the teaching-learning path by not only giving general indications but also presenting data relating to a specific context.

From a methodological point of view, the first issue was to identify the tool: children's use of robots is spreading to increasingly lower age ranges, such as those in kindergarten and in the first grade of primary school. For children in these age groups, it is difficult to use a questionnaire as a survey tool because the children may lack basic reading and writing skills. What remains feasible is the use of drawings that represent the mastered language for this particular age group.

In order to conduct the research, as a sample, two first-grade classes were selected from the primary school "N. Scarano" in the institute "G.A. Colozza" in Campobasso (Italy). Forty-four 6-year-old children, 23 females and 21 males, took part in the research. Obviously, the sample is not statistically significant; nonetheless, it reflects a specific local context. Another consideration to make is that the study is a preliminary research effort that aims not to test hypotheses, but rather to identify elements of children's imagination in relation to robots, to be verified in further systematic investigations. Children were simply asked to draw a robot without giving them any additional indications. A further and subsequent request consisted in asking the children to draw their favourite toy in order to grasp the difference between robots and toys.

All the drawings were scanned, published online and numbered in order to allow the correct link:

- Sezione 1 Robot: drawings of robots made by the children of the first group, https://www.flickr.com/photos/mickeypaco7/sets/72157676864473084/;

- Sezione 1 Giocattoli: drawings of toys made by the children of the first group, https://www.flickr.com/photos/mickeypaco7/sets/72157676954251933/;

- Sezione 2 Robot: drawings of robots made by the children of the second group, https://www.flickr.com/photos/mickeypaco7/sets/72157678254807812/;

- Sezione 2 Giocattoli: drawings of toys made by the children of the second group, https://www.flickr.com/photos/mickeypaco7/albums/72157680359379366.

\section{Interpretative criteria and results}

From a methodological point of view, the second issue was to identify the criteria to be used in analysing the drawings. A series of indications is provided by the works of Sarah Woods and Leopoldina Fortunati. A second group emerged after the first examination of the drawings.

- The first criterion is designed to identify the prevalence of either the anthropomorphic aspect or the mechanical element, following and simplifying Woods' approach, which distinguishes among mechanical robots, humanoids and zoomorphic robots while selecting the images of robots (Woods 2006, p. 1391).

- The second criterion, which has already been indicated in previous research (Bumby Dauttenhahn 1998, Woods 2006, p. 1394), considers the gender and aims to identify whether, and in what percentage, robots are assigned a gender.

- The third criterion relates to the presence or absence of emotions: this is also a known fact (Woods 2006, p. 13951397) and plays an important role in determining both how children relate to robots and how they perceive the difference between a person and a robot (Fortunati et al. 2015, p. 693).

- The fourth criterion, synthetically indicated with the term 'children', has been introduced a posteriori, after an initial examination of the drawings. Smaller robots were drawn next to bigger ones, and when the children were asked who they were, they explained that the smaller ones were offsprings.

- The fifth criterion refers to a question in the questionnaire used by Fortunati et al. (2015, p. 688): "Do you know cartoons or other TV programs or movies with robots?). Children's imagination is influenced by what is offered by the media created by adults for children. It is important to be able to grasp what most affects children's imagery and to what extent it is a significant feature, in order to join forms of informal learning with formal paths of the education system.

- The sixth criterion, similar to the fourth, was introduced a posteriori, after an initial examination of the drawings: the use, or at least the knowledge of digital instruments, such as the smartphone, in the first place may constitute an element of children's imagery regarding robots.

- The seventh and eighth criteria, indicated with the terms 'absolute coherence' and 'relative coherence', arise from the intention, based on the indication by Fortunati et al. (2015, p. 693) on the relationship between robots and toys. The absolute coherence considers the coherence between the child's favourite toy and the robot, showing a strong link between play and robot and highlighting ludic practices that can be functional to the integration of formal and 
non-formal learning paths. The relative coherence considers the relation between the child's favourite toy and the profile that emerges from other criteria: the prevalence of an anthropomorphic vision and the presence of gender indications, which are well connected with the indication of a doll being a child's favourite toy and can be indicators of how the toy influences the child's imagery of the robot.

Table 1 Overall results $(\mathrm{n}=44$ students $)$

\begin{tabular}{lllllll}
\hline Feature of robot & $\begin{array}{l}\text { Students } \\
(\mathbf{n = 4 4 )}\end{array}$ & $\mathbf{\%}$ & $\begin{array}{l}\text { Female }(\mathbf{n = 2 3} \\
\text { students) }\end{array}$ & $\mathbf{\%}$ & $\begin{array}{l}\text { Male (n=21 } \\
\text { students) }\end{array}$ & $\mathbf{\%}$ \\
\hline Anthropomorphic & 42 & $95.4 \%$ & 23 & $100.0 \%$ & 19 & $90.4 \%$ \\
Mechanical & 2 & $4.5 \%$ & 0 & $0.0 \%$ & 2 & $9.5 \%$ \\
Gender & 11 & $25.0 \%$ & 10 & $43.4 \%$ & 1 & $4.7 \%$ \\
Emotion & 13 & $30.2 \%$ & 8 & $34.7 \%$ & 5 & $23.8 \%$ \\
Children & 8 & $18.1 \%$ & 7 & $30.4 \%$ & 1 & $4.7 \%$ \\
Comics & 2 & $4.5 \%$ & 1 & $4.3 \%$ & 1 & $4.7 \%$ \\
Digital device & 7 & $15.9 \%$ & 5 & $21.7 \%$ & 2 & $9.5 \%$ \\
Absolute coherence & 8 & $18.1 \%$ & 0 & $0.0 \%$ & 8 & $38.0 \%$ \\
Relative coherence & 39 & $88.6 \%$ & 19 & $82.6 \%$ & 20 & $95.2 \%$ \\
\hline
\end{tabular}

The overall results (Table 1) show a strong prevalence of an anthropomorphic vision of the robot. As a mode of analysis, the prevalence of an anthropomorphic vision is given by all those drawings in which the robot has the shape of the human body with a recognisable head, arms and legs. When analysing the data by gender, the prevalence comes to $100 \%$ for girls and $90.4 \%$ for boys. The reporting of gender differences involves a quarter of all the drawings, but this is a peculiarity mainly for girls, with $43.4 \%$ against $4.7 \%$ for boys. The attribution of emotions to robots, mainly detectable with a smiling expression, covers almost 30\%, with a higher presence among girls (34.7\% against $23.8 \%$ ). The presence of small robots, intended as offsprings, covers $18 \%$ of the drawings, again with a stronger prevalence among girls (30.4\% against $4.7 \%)$. The reference to comics, cartoons or movies seems to be limited: only $4.5 \%$, with a substantially equal percentage from the gender point of view. The reference to digital tools is present in $15.9 \%$ of the drawings and is mainly detectable in the smartphone keyboard (Fig. 2). It should be noted that the reference to the smartphone turns out to be more than double among girls than among boys $(21.7 \%$ against $9.5 \%)$. The absolute coherence, namely, the one between the favourite toy and robot, is limited to $18.1 \%$ (and exclusively concerns males), thus showing the existence of limited ludic practices with robots, while what turns out to be understandably high is the coherence between favourite toy and the overall profile.

\section{Discussion and perspectives}

The research is limited due to the use of a statistically small sample; however, from the results, it is possible to put forward a number of research hypotheses to be examined through further investigation and to provide some guidance in terms of instructional design for any relative path specific to the context that has been examined.

An initial general observation is the following: due to the increasingly pervasive presence of robots and the earlier contact that children have with them, research and its methodology must take into account the prospect of analysing children's imagination in lower age groups and of using the language of images.

One fact that emerges, and this is the second observation, concerns the possible sources of the child's imagery: what seems to have most influence are the practices and the knowledge related to the use of the smartphone rather than to a more traditional reference, although present, to the world of comics, cartoons and movies. One particular drawing turns out to be the most symbolic (Fig. 2): the robot is drawn as a smartphone with legs and arms. 


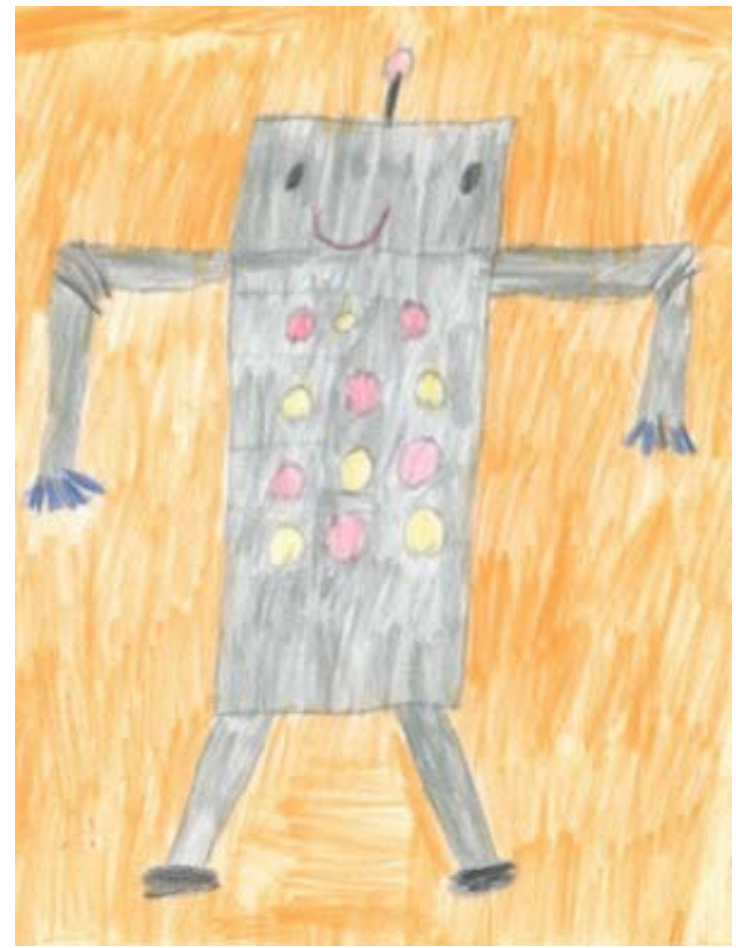

Fig. 2 Smartphone/robot.

The third observation is that compared to older age groups, what seems to be less pronounced is the distinction between play, robots and humans. Even taking into account, in relation to the specific context in which the research was carried out, that there do not seem to be many ludic activities with robots (absolute consistency: 20.4\%); the following should be emphasised:

- Robots are designed mainly in such an evident anthropomorphic shape as to assume a lack of awareness of the difference between human beings and robots. In this sense, what should be adopted are accurate analytical criteria that go beyond generic similarity with the human aspect: in some images, the reference to the robot is limited to secondary aspects such as squared facial features (Fig. 3). Furthermore, beyond the specific case, if what has been demonstrated for the 9- to 14-year age range is the children's ability (or inability) to distinguish among play, robots and humans (Fortunati et al. 2015, p. 693), this should also be determined with a larger sample of children at a younger age;

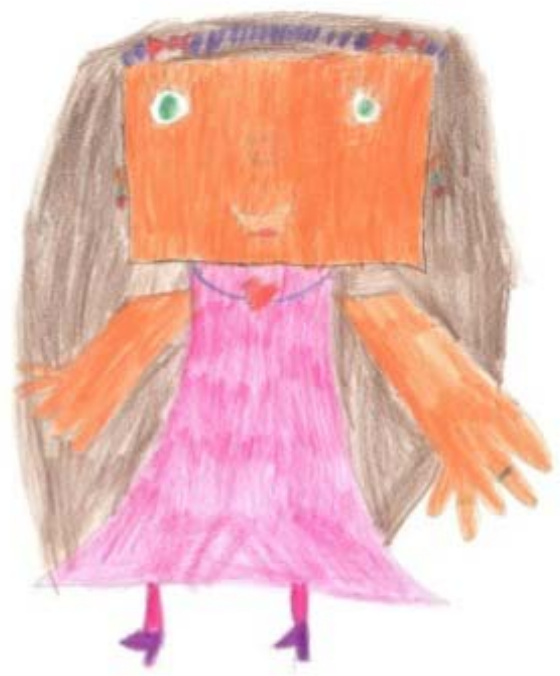

Fig. 3 An anthropomorphic robot.

- in relation to gender differences, what has been reported by Woods (2006, p. 1412) is confirmed. A significant number of children assign a gender to robots, although it seems more common among girls, perhaps due to a form 
of continuity with traditional toys such as dolls. Moreover, the distinction between play and robots seems to be more nuanced compared to older groups;

- the attribution, to a significant extent, of emotions to robots and, to a lesser extent (but not for girls), of parental relationships (Fig. 4) again makes thin the difference between robot and humans on one side, and traditional forms of play on the other;

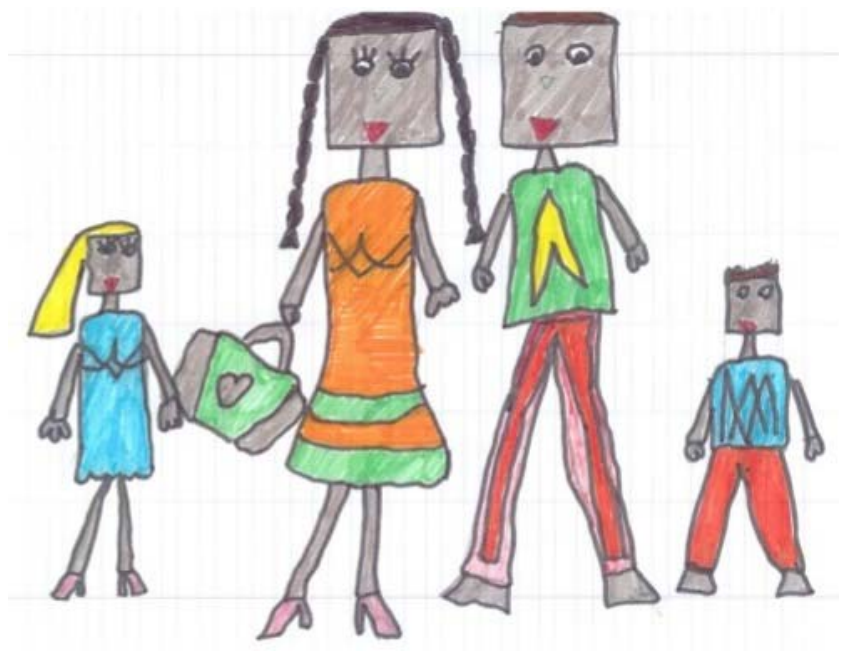

Fig. 4 Robot parental relationships.

- the fourth and final observation is related to the instructional design of training paths in which robots are used. There are already general indications in relation to the 9- to 11-year age group (Woods 2006, p. 141), but using drawings to grasp children's imagination of robots can constitute a way to gather functional data in order to choose a specific type of robot in relation to the specific context. In a situation as the one examined, the suggestion is to use highly zoomorphic or anthropomorphic robots, which can create involvement by the bond that children have with toys and existing recreational practices.

\section{Conclusions and prospects for future research}

As we have already indicated, considering the ongoing changes by which children show increasingly earlier familiarity with digital devices, the usefulness and the opportunity to investigate children's imagery in relation to robots in the age range of 5-9 years seem evident. The use of children's drawings is an appropriate survey tool from which emerges, as a fundamental issue in relation to the sample used, children's difficulty in distinguishing between toys and robots. The signs that support such a result originate mainly from children's attribution of emotions and gender to robots. The sample used does not allow, because of its reduced size, to generalise the results, which instead need to be verified through broader data, by checking, and eventually widening, in particular, the analytical criteria of the drawings.

There are also some indications that should be taken into account for future research. The first indication is linked to the other digital practices of children: the use of tablets, computers and smartphones builds a skill set that can hardly be distinguished from children's robot-based imagination by creating mutually beneficial forms that deserve to be further investigated. The second indication relates to children's relationship with toys and game: although there is a relationship in the examined sample, it is not particularly marked. However, this is a significant tie that is likely to be shared with other digital devices. The ludic dimension in the imagery and in robot-related practices is an element that should also be kept in mind. The third and last indication regards media education and educational paths. Initially, the introduction of robots cannot be separated from an analysis of children's imagination: the choice of the robots from among the different robot types, as well as their use, can be guided by such an analysis. Further research development may be linked to identifying and evaluating the learning strategies when using robots: a continuity strategy that links play with other digital practices for the acquisition of competences either can counteract or be linked to a reflexive and critical strategy that is needed to capture the gap and the difference among people, toys and robots.

\section{References}

Alessandri, G. (2015). Didattica e tecnologie. Intersezioni. Complessità, coding, robotica educativa. Roma: Anicia. Alimisis, D. (2013). Educational robotics: Open questions and new challenges, Themes in science and technology education, $\operatorname{VI}(1), 63-71$. 
Benitti, F.B.V. (2012). Exploring the educational potential of robotics in schools: A sistematic review, Computers \& Education, LVIII(3), 978-988.

Besio, S. (Ed.) (2008). Critical factors involved in using interactive robots for education and therapy of children with disabilities. Trento: UNI Service.

Bumby, K.E., Dautenhahn, K. (1999 august), Investigating children's attitudes towards robots: a case study. Paper presented at the Cognitive Technology Conference, USA, San Francisco.

Cook, A.M., \& Polgar, J.M. (2015). Assistive Technologies: Principles and Practice. St. Louis, Missouri: Elsevier/Mosby.

Eguchi, A. (2014), Educational robotics for promoting $21^{\text {st }}$ century skills. Journal of Automation, Mobile Robotics \& Intelligent Systems. VIII(1), 5-11.

European Parliament (2017). Civil Law Rules on Robotics. Retrieved from http://www.europarl.europa.eu/sides/getDoc.do?pubRef=-//EP//NONSGML+TA+P8-TA-2017$0051+0+\mathrm{DOC}+\mathrm{PDF}+\mathrm{V} 0 / / \mathrm{EN}$.

Fortunati, L., Esposito, A., Sarrica, M., \& Ferrin, G. (2015). Children's knowledge and imaginary about robots, International journal of social robotics, VII(5), 685-695.

Grimaldi, R. (ed.) (2015). A scuola con i robot. Innovazione didattica, sviluppo delle competenze e inclusione sociale. Bologna: Il Mulino.

Jenkins, H., Purushotma, R., Weigel, M., Clinton, K., \& Robinson, A. (2009). Confronting the Challenges of Participatory Culture: Media Education for the 21st Century. Cambridge, MA: The MIT Press.

Lepri, C. (2016). Le immagini raccontano. L'iconografia nella formazione dell 'immaginario infantile. ETS: Pisa.

Marcianò, G. (2017). Robot \& scuola. Guida per la progettazione, la realizzazione e la conduzione di un Laboratorio di Robotica Educativa (LRE). Milano: Hoepli.

Pennazio, V. (2016). Didattica, gioco e ambienti tecnologici inclusivi. Milano: Franco Angeli.

Thomaz, S., Aglaé, A., Fernandez, C., Pitta, R., Azevedo, S., Burlamaqui, A., Silva, A., \& Gonçalves, L.M.G. (2009 october), RoboEduc: A Pedagogical Tool to support educational Robotics. Paper presented at $39^{\text {th }}$ ASEE/IEEE frontiers in Education Conference, USA, Texas, San Antonio.

Toh, L.P.E., Causo, A., Tzuo, P.W., Chen, I.M., \& Yeo, S.H. (2016). A Review on the Use of Robots in Education and Young Children. Educational Thechnology \& Society, IXX(2), 148-163.

Turkle, S. (2011). Alone Together. Why We Expect More from Technology and Less from Each Other. New York: Basic Books.

Wing, J.M. (2006). Computational thinking. Communication of the ACM, ILIX(3), 33-35.

Woods, S. (2006), Exploring the design space of robots: Children's perspectives. Interacting with Computers, XVIII, 1390-1418.

Wunenburger, J.J. (2003). L'imaginaire. Paris: Presses Universitaires de France. 